\title{
A highly-concentrated poly(ethylene carbonate)-based electrolyte for all-solid-state Li battery working at room temperature
}

\author{
Kento Kimura, Mari Yajima, Yoichi Tominaga* \\ Graduate School of Bio-Applications and Systems Engineering, \\ Tokyo University of Agriculture and Technology, Koganei, Tokyo 184-8588, Japan
}

\begin{abstract}
We report an all-solid-state Li rechargeable battery based on a hybrid membrane comprising a highly-concentrated poly(ethylene carbonate) (PEC) electrolyte with $80 \mathrm{wt} \%$ of lithium bis(fluorosulfonyl)imide (LiFSI) and a three-dimensionally ordered macroporous polyimide matrix operating at room temperature. The PEC-LiFSI 80 wt\% electrolyte showed an ionic conductivity of the order of $10^{-5} \mathrm{~S} \mathrm{~cm}^{-1}$ at $30{ }^{\circ} \mathrm{C}$ and quite high $\mathrm{Li}$ transference number, and was employed as a good ion-conductive solid polymer membrane for all-solid-state Li battery. To assure the mechanical stability, the polyimide matrix was combined as a porous substrate to support the electrolyte. A Li|PEC-LiFSI|LiFePO ${ }_{4}$ cell with the hybrid membrane delivered a reversible charge-discharge capacity close to $120 \sim 130$ $\mathrm{mAh} \mathrm{g}^{-1}$ at $30{ }^{\circ} \mathrm{C}$ and $\mathrm{C} / 20$ rate.
\end{abstract}

*Corresponding author: ytominag@cc.tuat.ac.jp 


\section{Introduction}

All-solid-state configuration is the eventual goal for batteries, principally for Li rechargeable batteries, to realize greater energies without safety issues associated with volatile and flammable liquid electrolytes [1,2]. Solid polymer electrolytes (SPE) [3,4], mainly poly(ethylene oxide) (PEO) complexes with metal salts, have thus gained great attention. Nevertheless, slow Li-ion conduction in PEO prevents SPE from being used for practical batteries. One of major causes is excessive ion-dipole interaction between polar ether oxygen atoms and Li ions, which inhibits both segmental motion of polymer chains and fast migration of Li ions. Highly-crystalline nature of polyethers has also considerably delayed further success. Consequently, effective operation of PEO-based all-solid-state batteries below the melting point of PEO (ca. $60 \sim 65^{\circ} \mathrm{C}$ ) is almost impossible at this point.

Carbonate-based organic solutions are commonly used as electrolytes in commercially available Li-ion batteries because of their high dielectric constant. It has also been reported that several species of polycarbonates conduct ions [5-9] although relatively little effort has been devoted to develop polycarbonate-based SPE. Recently, Mindemark et al. have reported a solid-state $\mathrm{Li}$ polymer cell based on $\varepsilon$-caprolactone/trimethylene carbonate copolymer [9], similar in concept to the present study. In this communication, we report another approach utilizing amorphous poly(ethylene carbonate) (PEC) as a polymer host for SPE. Poly(alkylene carbonate)s, including PEC, are synthesized by alternating 
copolymerization of carbon dioxide $\left(\mathrm{CO}_{2}\right)$ with epoxides. Since this synthesis was first developed by Inoue and co-workers in 1968 [10], motivated by a concept of $\mathrm{CO}_{2}$ utilization, numerous efforts have been made to develop novel catalysts [11-13]. In this context, we have initially proposed to evaluate the $\mathrm{CO}_{2}$ /epoxide copolymers as polymer hosts for SPE $[14,15]$. We have found that highly-concentrated PEC-Li salt electrolytes interestingly show high ionic conductivity [16,17] and also extremely high Li transference numbers [17]. In the present study, we report an all-solid-state $\mathrm{Li}|\mathrm{SPE}| \mathrm{LiFePO}_{4}$ cell with a hybrid membrane based on a highly-concentrated PEC-LiFSI electrolyte and three-dimensionally ordered macroporous polyimide matrix.

\section{Experimental}

Poly(ethylene carbonate) (PEC, $M_{\mathrm{n}}=3.1 \times 10^{4}, M_{\mathrm{w}} / M_{\mathrm{n}}=3.9$ from GPC) was purchased from Empower Materials, USA. PEC was precipitated from acetonitrile solution into excess methanol and dried under vacuum at $60{ }^{\circ} \mathrm{C}$ for $24 \mathrm{~h}$ before use. Lithium bis(fluorosulfonyl)imide (LiFSI, battery grade) was purchased from Kishida Chemical Co., Japan, and used without further purifications. A three-dimensionally ordered macroporous (3DOM) polyimide matrix with an average pore diameter of $0.3 \mu \mathrm{m}$ and a thickness of $30 \mu \mathrm{m}$ was prepared by a colloidal crystal templating method [18]. For the preparation of an electrolyte/polyimide matrix hybrid membrane, the PEC and LiFSI at a ratio of 20:80 in 
weight were dissolved into acetonitrile and the solution was poured onto the polyimide matrix in a Teflon ${ }^{\circledR}$ dish, and dried under vacuum at $60{ }^{\circ} \mathrm{C}$ for $24 \mathrm{~h}$.

Ionic conductivity of the hybrid electrolyte was determined by electrochemical impedance spectroscopy (EIS) using an SP-150 (Bio-Logic Instrument, France) for symmetric cells with two stainless steel electrodes. Differential scanning calorimetry (DSC) measurement was performed using a DSC7020 (Hitachi High-Tech, Japan) within a temperature range of $-70{ }^{\circ} \mathrm{C}$ to $110{ }^{\circ} \mathrm{C}$ at a heating/cooling rate of $10{ }^{\circ} \mathrm{C} \mathrm{min}{ }^{-1}$ under a dry $\mathrm{N}_{2}$ gas. Linear sweep voltammetry (LSV) was carried out for a two-electrode cell comprising a stainless steel as working electrode, a $\mathrm{Li}$ as counter and reference electrodes and the hybrid electrolyte using SP-150 at $30{ }^{\circ} \mathrm{C}$ and a scan rate of $0.1 \mathrm{mV} \mathrm{s}^{-1}$.

A composite cathode was prepared by blending $\mathrm{LiFePO}_{4}$ (Tatung Fine Chemicals Co., Taiwan), poly(vinylidene fluoride) (PVdF, KYNAR 741, ARKEMA Co., France) and acetylene black (Denka Black ${ }^{\circledR}$, Denka Co., Japan) in a composition of 90:6:4 in weight. These components were mixed with $N$-methyl-2-pyrrolidinone (NMP, >99.5\%, Kanto Chemical Co., Japan), cast onto an $\mathrm{Al}$ current collector, and dried under vacuum at $85{ }^{\circ} \mathrm{C}$ for $24 \mathrm{~h}$. The active material loading was estimated to be $1.93 \mathrm{mg} \mathrm{cm}^{-2}$.

A CR2032 coin-type half-cell using the $\mathrm{LiFePO}_{4}$ cathode and a $\mathrm{Li}$ foil (Honjo Metal Co., Japan) anode was assembled for a battery test. The polyimide matrix and the cathode were cut into a circle shape and placed in a coin cell pan. An acetonitrile solution of PEC 
and LiFSI was separately prepared and cast onto the cell pan. Finally, the solvent was removed by the same drying condition of the hybrid electrolyte. A galvanostatic charge-discharge cycling of the cell was performed using a HJ1001SM8A system (Hokuto Denko Co., Japan) at $30{ }^{\circ} \mathrm{C}$ with various C-rates (1 C equals to $0.46 \mathrm{~mA}$ ) within a voltage range of 2.5 to $4.0 \mathrm{~V}$. The cell was kept at $30{ }^{\circ} \mathrm{C}$ for $15 \mathrm{~h}$ before the cycling. The cell assembly was carried out in an Ar gas-filled glovebox with the content of water and oxygen controlled below 1 ppm.

\section{Results and discussion}

As we have reported previously [17], a highly-concentrated PEC-LiFSI electrolyte forms homogeneous and transparent solid and shows a reasonable conductivity, although it is too soft and sticky to handle as a self-standing membrane. To overcome the difficulty in handling of the concentrated electrolyte, we tried to enhance the mechanical stability by employing a "pore-filling" technique, filling functional polymer materials into porous substrates [19]. In the present study, we utilized a 3DOM polyimide matrix which was prepared by Kanamura and co-workers as a porous substrate. They have developed the porous polyimide as a matrix for composite proton-conducting membranes of a direct methanol fuel cell [18]. Consequently, the membranes show good suppression of methanol cross-over without sacrificing conductivity because of the presence of highly-ordered 
macropores and an improvement of the mechanical stability.

We measured ionic conductivity of the hybrid membrane of PEC-LiFSI 80 wt\% electrolyte with the polyimide matrix as seen in Fig. 1. The conductivity was recorded to be $1.6 \times 10^{-5} \mathrm{~S} \mathrm{~cm}^{-1}$ at $30{ }^{\circ} \mathrm{C}$, which was a value only slightly lower than that of the original PEC-LiFSI electrolyte without the polyimide matrix $\left(2.5 \times 10^{-5} \mathrm{~S} \mathrm{~cm}^{-1}\right)$. In addition, the DSC trace was also nearly identical to the original electrolyte [17], indicating the glass transition temperature $\left(T_{\mathrm{g}}\right)$ at $-47{ }^{\circ} \mathrm{C}$. The pore-filling approach effectively assures the mechanical stability without sacrificing ion-conductive performance of the PEC-LiFSI electrolyte, as in the case of the proton-conducting system mentioned above. The anodic electrochemical stability of the composite electrolyte was also investigated by linear sweep voltammetry (LSV) as seen in Fig. 2. The electrolyte has a stability up to above $5 \mathrm{~V}$ vs. $\mathrm{Li} / \mathrm{Li}^{+}$, which may enable the use of $5 \mathrm{~V}$-class cathode materials for Li batteries.

An all-solid-state $\mathrm{Li}|\mathrm{SPE}| \mathrm{LiFePO}_{4}$ cell based on the hybrid membrane was successfully assembled by directly casting the electrolyte solution onto the cathode. As a result of galvanostatic battery cycling for the cell at $30{ }^{\circ} \mathrm{C}$, the charge-discharge profiles clearly show flat plateaus centered at $3.45 \mathrm{~V}$ which indicate the electrochemical reaction of $\mathrm{LiFePO}_{4}(\mathrm{Fig}$. 3a). This coin cell exhibited a reversible capacity close to $120-130 \mathrm{mAh} \mathrm{g}^{-1}$ at $\mathrm{C} / 20$ rate, and also delivered reasonable capacity ranging from 80 to $110 \mathrm{mAh} \mathrm{g}^{-1}$ at higher rates, i.e., $\mathrm{C} / 5$ and $\mathrm{C} / 10$, respectively. This performance is comparable to that of the previous 
copolymer-based system operated at room temperature [9]. Additionally, the extended data up to 30 cycles demonstrated the inhibitions of a short circuit failure caused by a Li dendrite growth and a mechanical instability, which were probably assured by the use of the polyimide matrix (Fig. 3b). Herein, what makes the battery operation at ambient temperature possible in the present system was the use of our unique PEC-based electrolyte. To confirm this feature, we also assembled the same coin cell with a conventional electrolyte based on an amorphous ethylene oxide/propylene oxide random copolymer (P(EO/PO), [EO]:[PO]=89:11) as a comparison by using the identical procedure with the use of the same polyimide matrix. The same cell system containing $\mathrm{P}(\mathrm{EO} / \mathrm{PO})$ electrolyte with $5 \mathrm{~mol} \%$ of LiFSI and the polyimide matrix exhibited charge-discharge capacities around 50 60 $\mathrm{mAh} \mathrm{g}^{-1}$ for first three cycles at $30{ }^{\circ} \mathrm{C}$ and $\mathrm{C} / 20$ rate. The difference in the conductivity at $30{ }^{\circ} \mathrm{C}$ of PEC-LiFSI (80 wt $\%, 2.5 \times 10^{-5} \mathrm{~S} \mathrm{~cm}^{-1}$ ) and $\mathrm{P}(\mathrm{EO} / \mathrm{PO})$-LiFSI ( $\left.5 \mathrm{~mol} \%, 3.4 \times 10^{-5} \mathrm{~S} \mathrm{~cm}^{-1}\right)$ is very small, and the lower delivered capacity of $\mathrm{P}(\mathrm{EO} / \mathrm{PO})$-based cell implies that the conductivity value is not the only factor to obtain better battery performance.

We think that i) high Li transference number $\left(t_{+}\right)$, ii) high Li salt concentration and iii) good adhesiveness, which are inherent in the PEC-LiFSI electrolyte, may lead to the good cell performance. We have previously confirmed the quite high $t_{+}$of PEC-LiFSI $80 \mathrm{wt} \%$ electrolyte over 0.5 [17], whereas it is hard to achieve such a high value for other bi-ion conductive SPE systems. High $t_{+}$value is favorable in terms of leading to not only high 
Li-ion conductivity which is the product of overall conductivity and $t_{+}$, but also less polarization of cell potential and less accumulation of anion-decomposed products on the cathode [20]. As for ii), favorable features of highly-concentrated electrolytes have recently been reported by some researchers for the standard liquid solutions [21,22]. The effect may arise from improvement in $t_{+}$and plenty of $\mathrm{Li}$ ions as carrier ions on the surface of the electrodes, as well as an enhanced electrochemical stability and a different solid electrolyte interphase (SEI) composition caused by the presence of aggregated ions. As for iii), relatively high adhesiveness of the PEC-based electrolyte should have a great effect to keep good contact with the active material during the charge-discharge process. It is also important to point out the preparation method that the electrolyte solution was directly cast onto the cathode might have improved the performance of the cell.

\section{Conclusions}

We have developed an all-solid-state, ambient temperature-operating Li|PEC-LiFSI|LiFePO 4 cell based on a hybrid membrane of a highly-concentrated PEC-based electrolyte and a macroporous polyimide matrix. The cell delivered a reversible charge-discharge capacity close to $130 \mathrm{mAh} \mathrm{g}^{-1}$ at $30{ }^{\circ} \mathrm{C}$ and $\mathrm{C} / 20$ rate. We assume that this performance was achieved by the inherent features of the highly-concentrated PEC-based electrolyte with $80 \mathrm{wt} \%$ of LiFSI, including a reasonable conductivity of the order of $10^{-5} \mathrm{~S}$ 
$\mathrm{cm}^{-1}$ at $30{ }^{\circ} \mathrm{C}$ and a high Li transference number over 0.5. The PEC-based electrolyte system may contribute to the development of safe and flexible energy device alternatives such as all-solid-state batteries in the near future.

\section{Acknowledgements}

This study was financially supported by the Specially Promoted Research for Innovative Next Generation Batteries of the Advanced Low Carbon Technology Research and Development Program (ALCA-SPRING) from the Japan Science and Technology Agency (JST), Japan. The 3DOM polyimide matrix was kindly donated from Prof. Kiyoshi Kanamura and Dr. Hirokazu Munakata of Tokyo Metropolitan University, Japan.

\section{References}

[1] J.M. Tarascon, M. Armand, Issues and Challenges Facing Rechargeable Lithium Batteries, Nature 414 (2001) 359.

[2] K. Xu, Electrolytes and Interphases in Li-Ion Batteries and Beyond, Chem. Rev. 114 (2014) 11503.

[3] M.A. Ratner, D.F. Shriver, Ion-Transport in Solvent-Free Polymers, Chem. Rev. 88 (1988) 109.

[4] W.H. Meyer, Polymer Electrolytes for Lithium-Ion Batteries, Adv. Mater. 10 (1998) 439.

[5] X. Wei, D.F. Shriver, Highly Conductive Polymer Electrolytes Containing Rigid Polymers, Chem. Mater. 10 (1998) 2307.

[6] M.J. Smith, M.M. Silva, S. Cerqueira, J.R. MacCallum, Preparation and Characterization 
of a Lithium Ion Conducting Electrolyte Based on Poly(trimethylene carbonate), Solid State Ionics 140 (2001) 345.

[7] B. Sun, J. Mindemark, K. Edström, D. Brandell, Realization of High Performance Polycarbonate-Based Li Polymer Batteries, Electrochem. Commun. 52 (2015) 71.

[8] J. Mindemark, L. Imholt, D. Brandell, Synthesis of High Molecular Flexibility Polycarbonates for Solid Polymer Electrolytes, Electrochim. Acta 175 (2015) 247.

[9] J. Mindemark, B. Sun, E. Törmä, D. Brandell, High-Performance Solid Polymer Electrolytes for Lithium Batteries Operational at Ambient Temperature, J. Power Sources 298 (2015) 166.

[10]S. Inoue, H. Koinuma, T. Tsuruta, Copolymerization of Carbon Dioxide and Epoxide, J. Polym. Sci., Part B: Polym. Lett. 7 (1969) 287.

[11]D.J. Darensbourg, Making Plastics from Carbon Dioxide: Salen Metal Complexes as Catalysts for the Production of Polycarbonates from Epoxides and $\mathrm{CO}_{2}$, Chem. Rev. 107 (2007) 2388.

[12] S. Klaus, M.W. Lehenmeier, C.E. Anderson, B. Rieger, Recent Advances in $\mathrm{CO}_{2} /$ Epoxide Copolymerization-New Strategies and Cooperative Mechanisms, Coord. Chem. Rev. 255 (2011) 1460.

[13]X.B. Lu, W.M. Ren, G.P. Wu, $\mathrm{CO}_{2}$ Copolymers from Epoxides: Catalyst Activity, Product Selectivity, and Stereochemistry Control, Acc. Chem. Res. 45 (2012) 1721.

[14] Y. Tominaga, T. Shimomura, M. Nakamura, Alternating Copolymers of Carbon Dioxide with Glycidyl Ethers for Novel Ion-Conductive Polymer Electrolytes, Polymer 51 (2010) 4295.

[15]M. Nakamura, Y. Tominaga, Utilization of Carbon Dioxide for Polymer Electrolytes II: Synthesis of Alternating Copolymers with Glycidyl Ethers as Novel Ion-Conductive Polymers, Electrochim. Acta 57 (2011) 36.

[16]Y. Tominaga, V. Nanthana, D. Tohyama, Ionic Conduction in Poly(ethylene 10 
carbonate)-Based Rubbery Electrolytes Including Lithium Salts, Polymer J. 44 (2012) 1155.

[17] Y. Tominaga, K. Yamazaki, Fast Li-ion Conduction in Poly(ethylene carbonate)-Based Electrolytes and Composites Filled with $\mathrm{TiO}_{2}$ Nanoparticles, Chem. Commun. 50 (2014) 648.

[18]H. Munakata, D. Yamamoto, K. Kanamura, Properties of Composite Proton-Conducting Membranes Prepared From Three-Dimensionally Ordered Macroporous Polyimide Matrix and Polyelectrolyte, Chem. Commun. 3986 (2005).

[19]T. Yamaguchi, F. Miyata, S. Nakao, Pore-Filling Type Polymer Electrolyte Membranes for a Direct Methanol Fuel Cell, J. Membr. Sci. 214 (2003) 283.

[20]F. Kaneko, S. Wada, M. Nakayama, M. Wakihara, J. Koki, S. Kuroki, Capacity Fading Mechanism in All Solid-State Lithium Polymer Secondary Batteries Using PEG-Borate/Aluminate Ester as Plasticizer for Polymer Electrolytes, Adv. Funct. Mater. 19 (2009) 918.

[21]L. Suo, Y.S. Hu, H. Li, M. Armand, L. Chen, A New Class of Solvent-in-Salt Electrolyte for High-Energy Rechargeable Metallic Lithium Batteries, Nature Commun. 4 (2013) 1481.

[22]Y. Yamada, K. Furukawa, K. Sodeyama, K. Kikuchi, M. Yaegashi, Y. Tateyama, A. Yamada, Unusual Stability of Acetonitrile-Based Superconcentrated Electrolytes for Fast-Charging Lithium-Ion Batteries, J. Am. Chem. Soc. 136 (2014) 5039. 


\section{Figure captions}

Fig. 1. Temperature dependence of ionic conductivity for the hybrid electrolyte membrane. Inset: DSC trace of the second heating scan for the same membrane.

Fig. 2. Linear sweep voltammogram of the hybrid electrolyte membrane at $30{ }^{\circ} \mathrm{C}$.

Fig. 3. (a) Potential profiles of all-solid-state $\mathrm{Li}|\mathrm{PEC}-\mathrm{LiFSI}| \mathrm{LiFePO}_{4}$ cell at $30{ }^{\circ} \mathrm{C}$ and various C-rates. The charge-discharge curves of 2nd, 11th, and 16th cycle are shown as examples of the behavior at $\mathrm{C} / 20, \mathrm{C} / 10$ and $\mathrm{C} / 5$ rates, respectively. (b) Delivered charge/discharge capacity and Coulomb efficiency of the Li|PEC-LiFSI|LiFePO ${ }_{4}$ cell at $30{ }^{\circ} \mathrm{C}$ as a function of cycle number. 


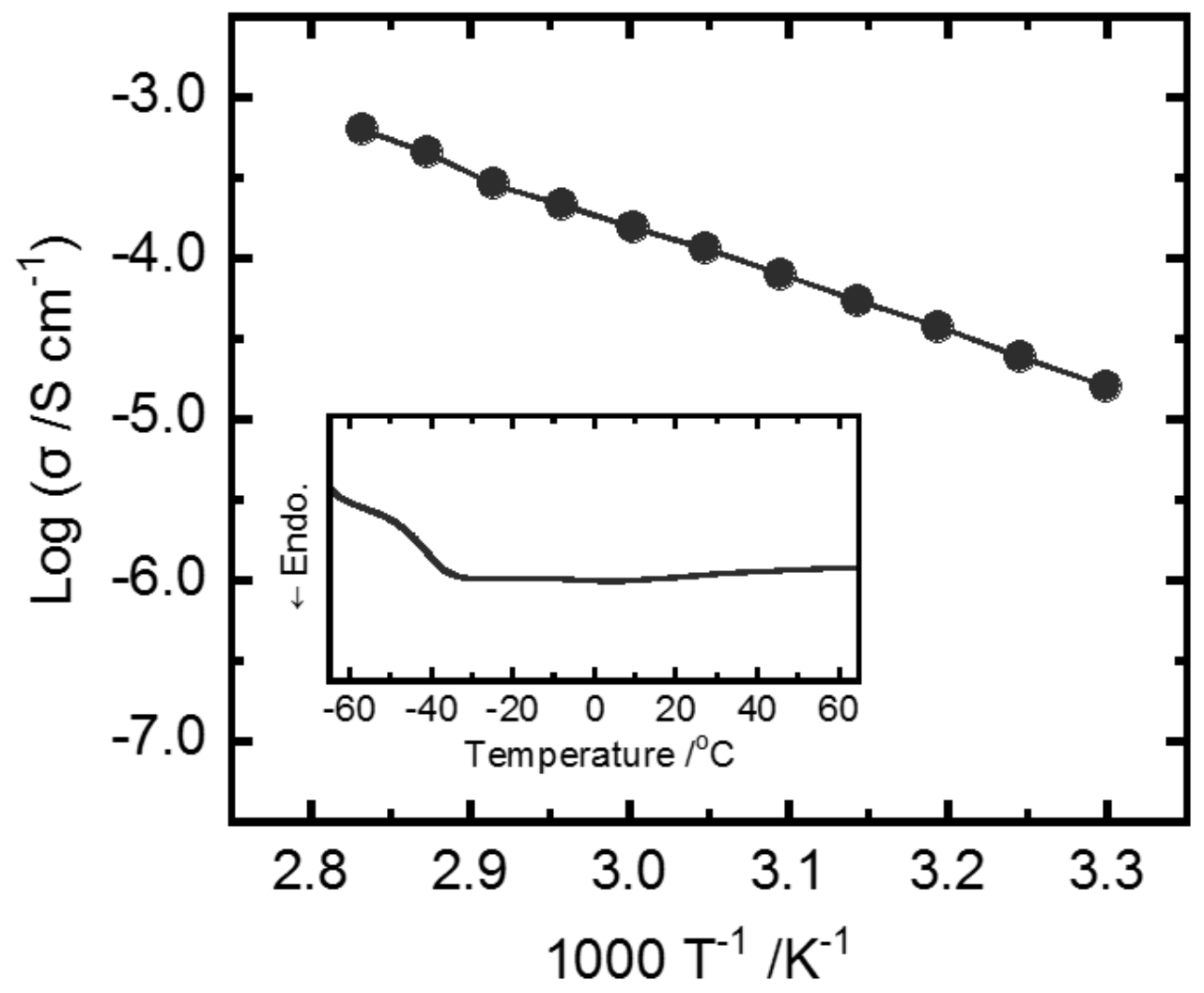

Fig. 1

Kimura, Yajima and Tominaga 


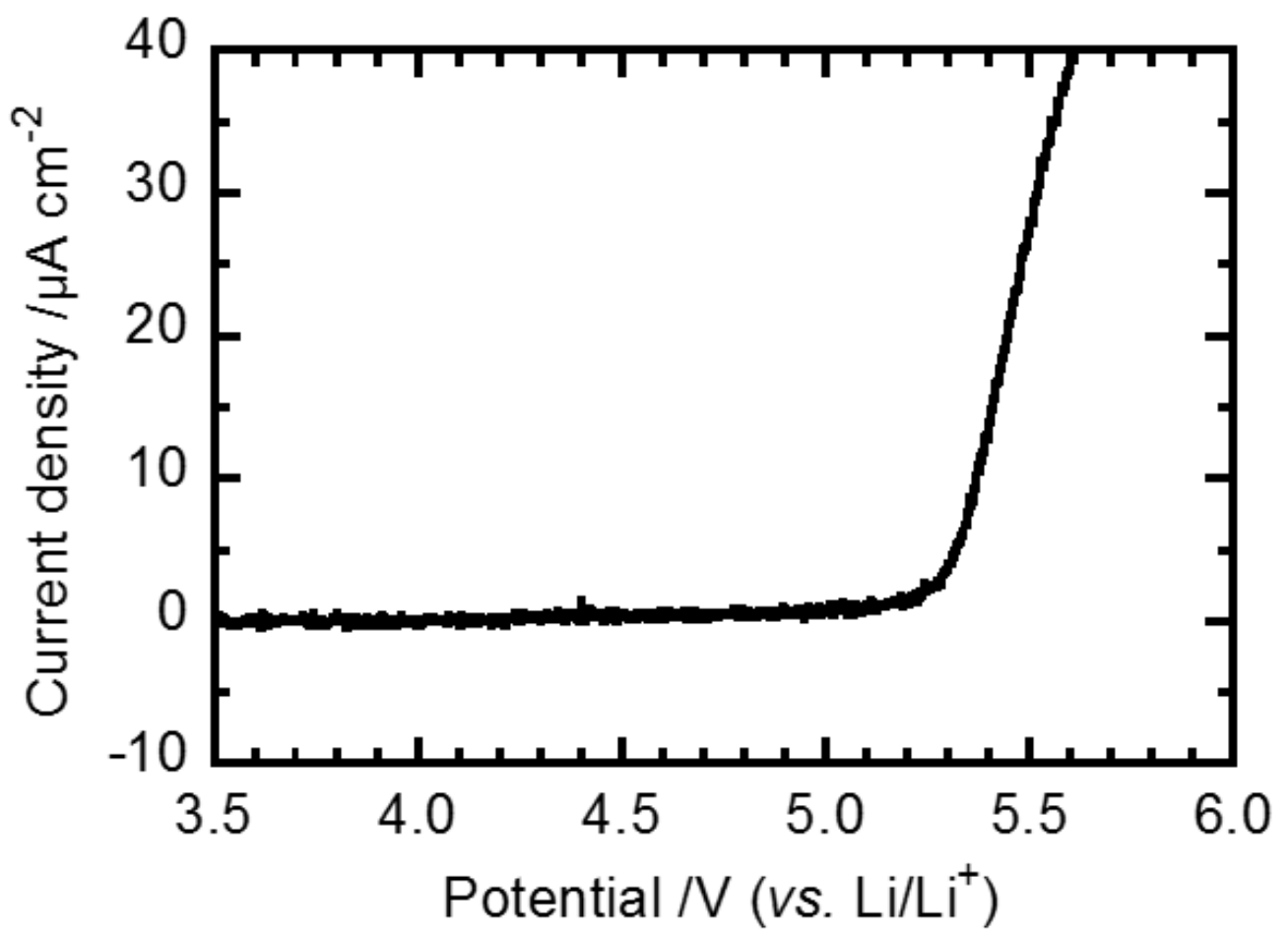

Fig. 2

Kimura, Yajima and Tominaga 
a)

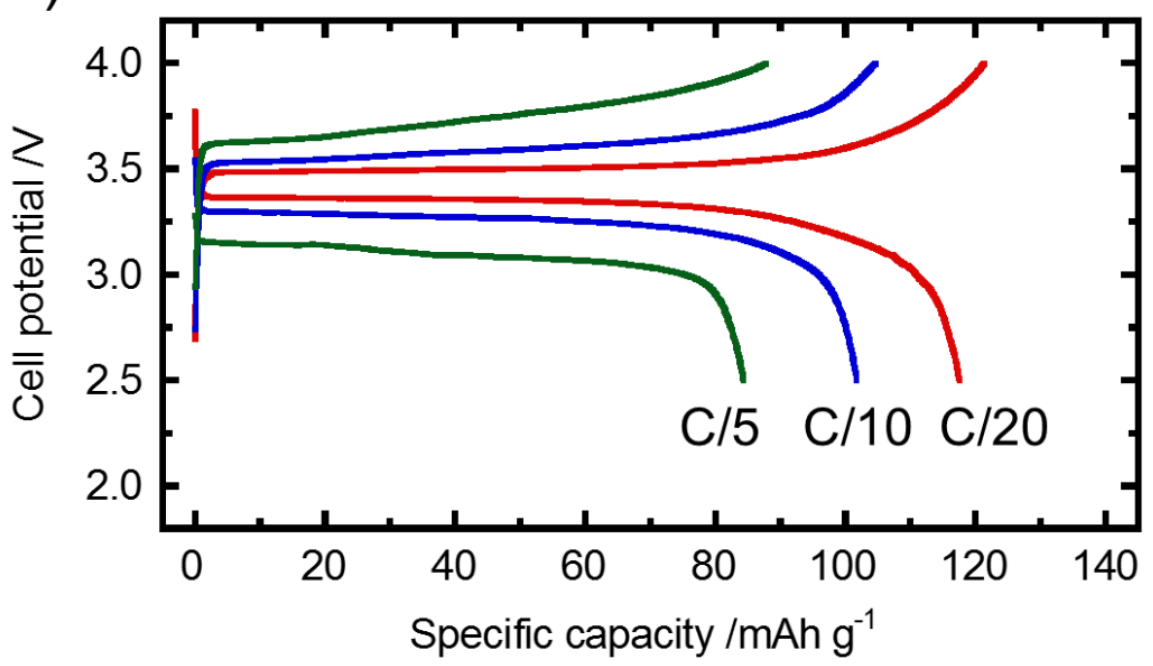

b)

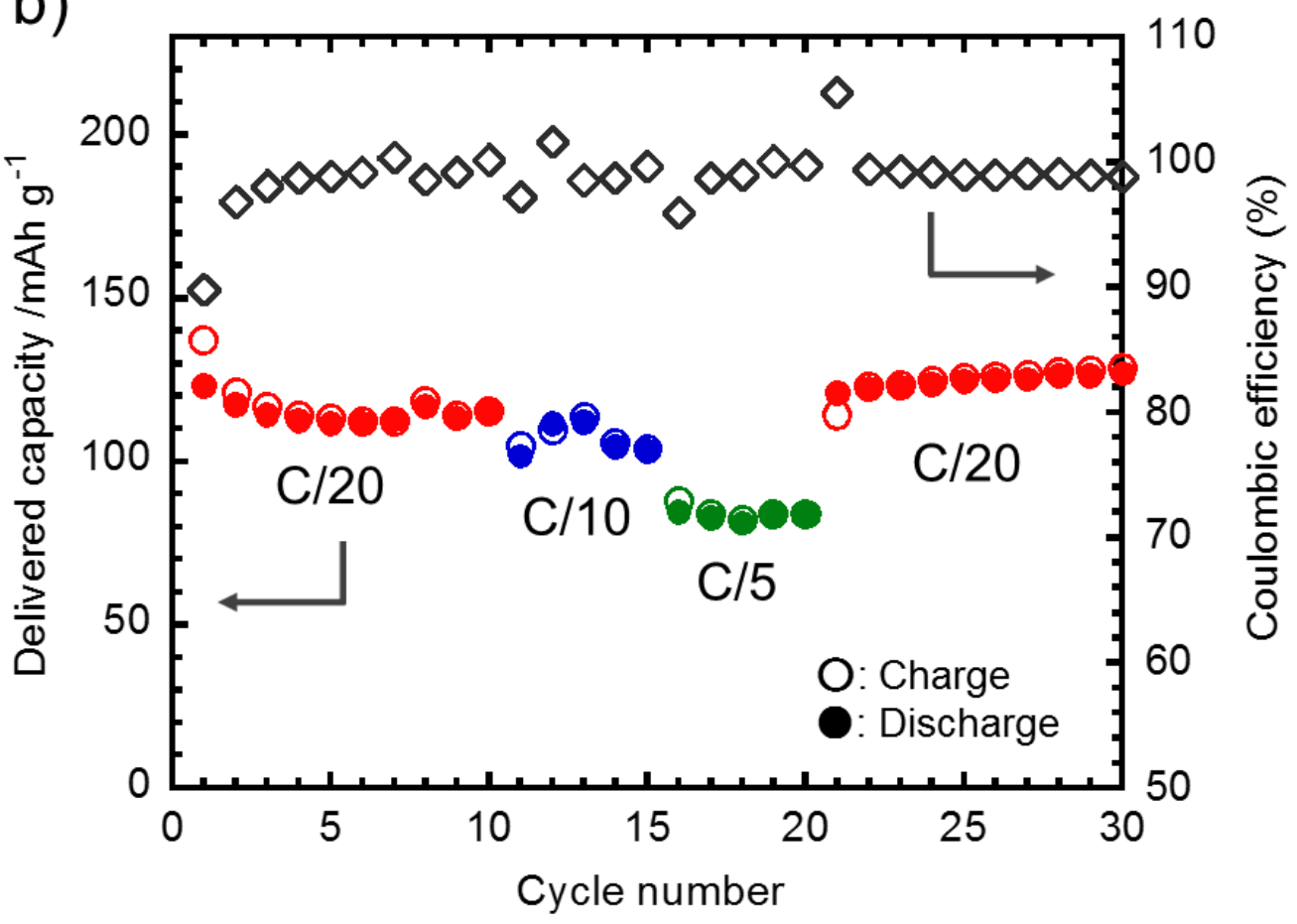

Fig. 3

Kimura, Yajima and Tominaga 